\section{PORCINE VALVES ARE REENDOTHELIALIZED BY HUMAN RECIPIENT ENDOTHELIUM IN VIVO}

The degeneration of human allogeneic and porcine xenogeneic heart valves has not been clearly understood. The question is whether the observed loss of function and calcification is primarily an immunologic process or a mechanical process or is influenced by both factors. In the current study, we looked at explanted xenogeneic heart valves for the presence of recipient endothelium. Explanted valves were shock frozen and stored at $-80^{\circ} \mathrm{C}$ before use. They were subsequently examined by immunohistochemical staining with a variety of monoclonal antibodies. Xenogeneic valves showed clearly positive results for the human major histocompatibility complex class I and class II antigens and morphologically showed a thin layer of viable endothelium restricted to the annular region of the valve. Additionally, they were also positive for intercellular adhesion molecule-1 and the $H-Y$ antigen. Although the xenogeneic valves were significantly degenerated, the endothelium was clearly defined and could be identified immunohistochemically as being of recipient origin. The grafts remained negative for endothelial cell-leukocyte adhesion molecule-1 and factor VIII. These data allow speculation on whether reendothelialization of valvular grafts with recipient endothelium is a normal repair mechanism in vivo. (J Thorac Cardiovasc Surg 1995;109:702-6)

N. Zavazava, MD, PhD, ${ }^{a}$ A. Simon, MD, ${ }^{a}$ H. H. Sievers, MD, PhD, ${ }^{b}$

A. Bernhard, $\mathrm{MD}, \mathrm{PhD},{ }^{\mathrm{c}}$ and W. Müller-Ruchholtz, $\mathrm{MD}, \mathrm{PhD},{ }^{\mathrm{a}}$

Kiel and Lübeck, Germany
$\mathrm{V}$ alvular replacement has come of age. Lam, Aram, and Munnell ${ }^{1}$ first tried the use of a homograft in the descending aorta of dogs in 1952. The nonfunctional aortic leaflets degenerated and fibrosed. It soon became apparent that allografts could only remain functional when subjected to a functional work load. ${ }^{2}$ Despite improved conservation and treatment, the degeneration of allografts still poses a major clinical problem. After about 7 years, allografts begin to show signs of wearing, calcification, and tearing. It is quite obvious that mechanical damage does play a role, but to what extent do immunologic factors contribute to the chronic loss of valves?

The immunogenicity of valves has been the subject of study by several groups, including ours. ${ }^{3-7}$

From the Institute of Immunology and Hospital of Cardiovascular Surgery, ${ }^{\mathrm{c}}$ University of Kiel, and Hospital of Heart Surgery, ${ }^{\mathrm{b}}$ University of Lübeck, Germany.

Received for publication April 21, 1994.

Accepted for publication Sept. 30, 1994.

Address for reprints: Nicholaus Zavazava, $\mathrm{PhD}$, Institute of Immunology, University of Kiel, Brunswikerstr. 4, 24105 Kiel, Germany.

Copyright $(\mathcal{C} 1995$ by Mosby-Year Book, Inc.

$0022-5223 / 95 \$ 3.00+0 \quad \mathbf{1 2} / \mathbf{1} / \mathbf{6 1 0 2 7}$
From these studies it has become apparent that murine and human valves express major histocompatibility complex (MHC) antigens and that cryopreservation does not abolish their immunogenicity. ${ }^{3}$ Our recent data showed that human valvular endothelium constitutively expresses class I and class II antigens. After stimulation with interferon gamma they show increased expression of adhesion molecules. These studies point to the fact that valves can sensitize the recipient and thus lead to accelerated graft degeneration. Experiments on mixed cell reactions, where vascular endothelium was used to stimulate $\mathrm{T}$ cells, showed enhanced allogeneic reaction in comparison with that of peripheral blood lymphocytes. ${ }^{7}$ Allografts or xenografts can sensitize the recipient only if a viable endothelial layer is present. Some studies have shown that cryopreserved valves still possess viable cells, ${ }^{8}$ but the methods used to test cell viability require further improvement.

In the current study we looked at the possibility of the in vivo reendothelialization of xenografts. In these studies we used immunohistochemical staining of explanted and nonfunctional xenografts.

\section{Materials and methods}

Explanted valves. Heart valves were obtained when insufficient xenografts $(n=4)$ or allografts $(n=5)$ were replaced, at transplantation, and at cardiac retransplanta- 
tion $(n=2)$. The explanted grafts were removed normally after at least 7 years. The valves were quickly shock frozen in liquid nitrogen until further use.

Fresh porcine valves. Porcine hearts were obtained from the slaughterhouse immediately after the animals were killed and delivered to the laboratory at $4^{\circ} \mathrm{C}$. The aortic, pulmonary, and mitral valves were removed and quickly shock frozen. Five-micrometer sections were cut and used for immunohistochemical staining as control specimens for the explanted xenogeneic grafts.

Antibodies. The clone for the W6/32 monoclonal antibody (anti-human leukocyte antigens $A, B$, and $C$ ) was obtained from the American Type Cell Culture. The clone was grown in culture and the supernatant purified over a protein A column (Pharmacia, Uppsala, Sweden). The antibody was concentrated to $1 \mu \mathrm{g} / \mathrm{ml}$ before use. The anti-DR antibody was purchased from Becton Dickinson, Oxnard, Calif. The anti-intercellular adhesion molecule-1 (ICAM-1), anti-endothelial cell-leukocyte adhesion molecule-1 (ELAM-1), anti-factor VIII (F-VIII), and anti$\mathrm{H}-\mathrm{Y}$ antibodies were obtained from Immunotech, France.

Immunohistochemical staining of explanted valves. Five-micrometer sections of explanted valves were fixed in acetone for 10 minutes and subsequently washed for 2 minutes in Tris-buffered saline. Antibodies were titrated between 1/10 and 1/50 for optimal stains. The sections were stained by the alkaline phosphatase-anti-alkaline phosphatase staining technique, as we previously described in more detail elsewhere. ${ }^{7}$ Only the sections stained with the ME1 were developed with the peroxidase enzyme.

\section{Results}

There was virtually no positive stain of the fresh porcine valves obtained from the slaughterhouse with any of the antibodies used. The anti-DR antibody had minimal affinity for the collagen fibers and stroma, but remained negative for porcine endothelial cells. The four antibodies, W6/32, anti-ICAM-1, anti-H-Y, and anti-DR, were positive on allografts as we previously reported. ${ }^{7}$ However, surprisingly, a monolayer of endothelial cells was clearly detectable on the xenografts. In Fig. 1, the anti-class I antibody strongly stained a monolayer of cells that had ovalshaped cell nuclei. These cells were morphologically identified as endothelial cells. Further evidence that the cells were endothelial was the observation that the cells were only identified on the annular region of the valves and not within the graft. This suggests that the cells that characteristically infiltrate the graft and would be distributed within the leaflets were not mononuclear. All xenografts studied ( $n=$ 4) were found to be positive for endothelial cells.

Additionally, the section in Fig. 1 shows the degeneration of the xenogeneic graft. Patches of calcification are clearly visible. Consequently the valves were difficult to cut in cryostat sections. The valves were hard and felt like plastic pads.

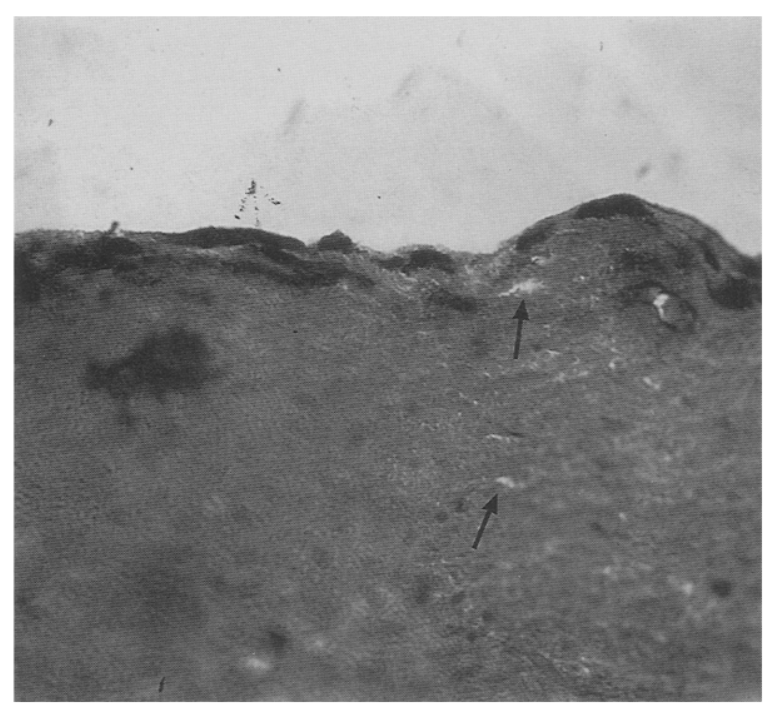

Fig. 1. Human endothelium on degenerated explanted valvular porcine xenograft. Five-micrometer section of porcine xenograft is stained with W6/32 monoclonal antibody that stains human class I antigens (anti-human leukocyte antigens A, B, and C). Monolayer of cells that have oval-shaped cell nuclei and strongly express class I antigens is observed. These cells are morphologically endothelial. Collagen fibers of valve are no longer intact and show signs of calcification (arrows), visible as white patches dissipated on graft (original magnification $\times 366$ ).

The sections were further stained with the H-Y antibody. A fine monolayer was stained (Fig. 2, A) confirming that the cells were endothelial, as we previously reported. ${ }^{7}$ For comparison, we stained a homograft to show the endothelium and the intensity of expression of the H-Y antigen (Fig. 2, B). The homograft had been obtained from an explanted heart that was insufficient. Further evidence for the presence of human endothelial cells on xenogeneic grafts was provided by the anti-DR antibody (Fig. 3 ). This antibody also stained the endothelial cells. This was expected inasmuch as we had previously reported on the weak expression of MHC class II antigens by endothelial cells. The ICAM-1 antibody stained strongly, whereas the ELAM-1 and F-VIII antibodies remained negative. These data are summarized in Table I.

\section{Discussion}

The degeneration of xenogeneic and allogeneic valve grafts is a serious clinical problem that is often accompanied by severe heart problems. Some of the reasons that lead to degeneration could be mechanical damage, but immunologic processes may play a 

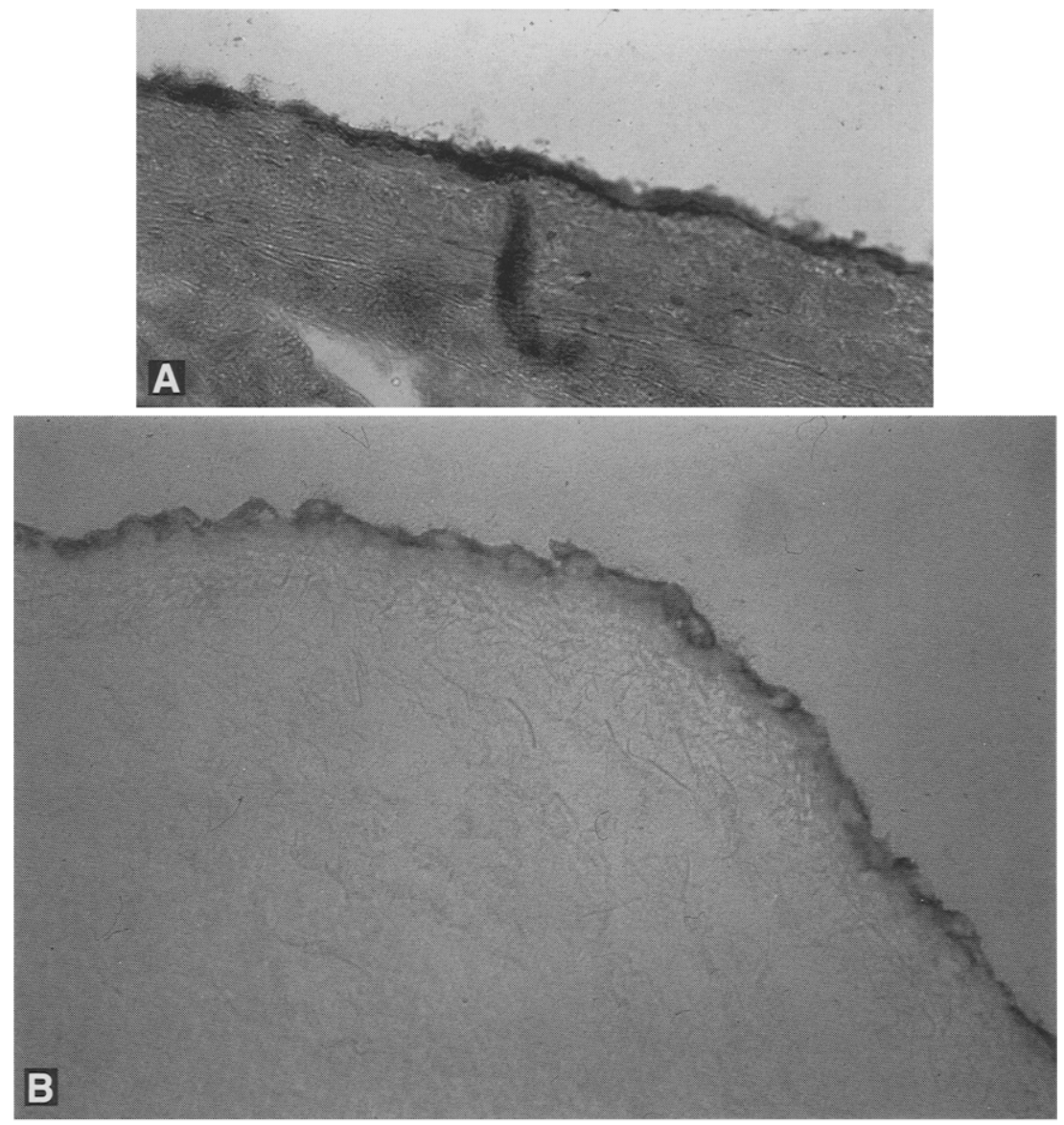

Fig. 2. A, Immunohistochemical staining of porcine valves with anti-H-Y antibody. Further evidence that monolayer identified in Fig. 1 is human endothelium is provided by H-Y antibody. Monolayer is also identified that is continuous on surface of valve. Signs of calcification are also visible here as small white patches below endothelial monolayer (original magnification $\times 180$ ). B, Homograft stained with H-Y antibody. Section was not stained with hemalaum solution to allow better differentiation of endothelium. Strongly stained monolayer of endothelial cells is clearly visible. Tissue of homograft was also well maintained, showing no signs of degeneration (original magnification $\times 180$ ).

significant role. Cryopreservation retains antigenicity by maintaining cell viability of fibroblasts and endothelial cells. Syngeneic tissue calcified far less than allogeneic tissue, suggesting immunologic processes. ${ }^{9}$ The aim of the current study was to examine the possibility of reendothelialization of xenografts with human endothelium. Our data show that xenogeneic grafts can be reendothelialized by human endothelium. To our knowledge this is the first description of reendothelialization of porcine xenografts by human endothelium.

O'Connell and colleagues ${ }^{10}$ have previously shown that endomyocardium of cardiac grafts can be reendothelialized by recipient endothelium in at least $30 \%$ of cases after cardiac transplantation.
These data suggest that reendothelialization is a natural repair mechanism after immunologic or mechanical damage and injury. The endothelial cell distribution was limited to the annular region of the leaflet. Presumably these cells originated from the aorta wall and wandered onto the porcine graft. The porcine valve matrix is obviously suitable for human endothelial cell adhesion.

Other groups have reported degeneration of valves in children ${ }^{6}$ and elderly patients. We examined the immunogenicity of human valvular endothelial cells in a recent paper. ${ }^{7}$ In this report we described the expression of $\mathrm{MHC}$ antigens and that of adhesion molecules on valvular endothelium. Antigen expression is a prerequisite for the immu- 
Table I. Summary of antigen expression by human endothelium found on xenogeneic valvular bioprotheses

\begin{tabular}{cc}
\hline \multicolumn{1}{c}{ Antigen } & $\begin{array}{c}\text { Expression intensity } \\
\text { on xenografts }\end{array}$ \\
\hline MHC class I & +++ \\
MHC class II & ++ \\
ICAM-1 & ++ \\
ELAM-1 & - \\
H-Y & ++ \\
F-VIII & - \\
\hline+++ , Very strong expression; ++ , strong expression; - , no expression.
\end{tabular}

nologic reactions that lead to degeneration of human valves. Cryopreserved valves with a viable endothelium can potentially present antigen to host $\mathrm{T}$ and $\mathrm{B}$ cells eliciting an immunologic reaction. Our previous data showed that valvular endothelium can stimulate $\mathrm{T}$ cells in a mixed cell reaction. Although the expression of class II antigens was low, cell stimulation was more enhanced than that by peripheral blood lymphocytes. However, Lupinetti and associates $^{4}$ failed to show a direct link between antigenicity and immunogenicity. These findings suggest that we may never be able to predict the fate of an allograft despite available knowledge on cell viability and immunogenicity before implantation.

The question that arises from our data is how reendothelialization of valves occurs in vivo. Does endothelial cell damage occur beforehand or can donor and recipient endothelium coexist? A careful study of the xenografts shows that the only endothelium present on the valves is positively stained by anti-human antibodies. Damaged donor endothelium is likely to be progressively replaced by recipient endothelium. Studies on microchimerism on recipient valvular allografts are now under way.

Recent data by Eberl and associates ${ }^{11}$ show the differences in the in vitro reendothelialization success of bioprotheses that have been fixed by different techniques. Should the bioprotheses be fixed in such a way that they can promote reendothelialization in vivo, we may be able to make the in vitro reendothelialization unnecessary by promoting the in vivo process. The potential of viable allografts to survive for a long time is supported by the data by Ross, Jackson, and Davies ${ }^{12}$ that show autologous pulmonary valves placed in the aortic position can successfully survive without any signs of degeneration. It appears therefore that factors contributing to the degeneration of bioprotheses are not only mechanical and immunologic, but also that the preceding

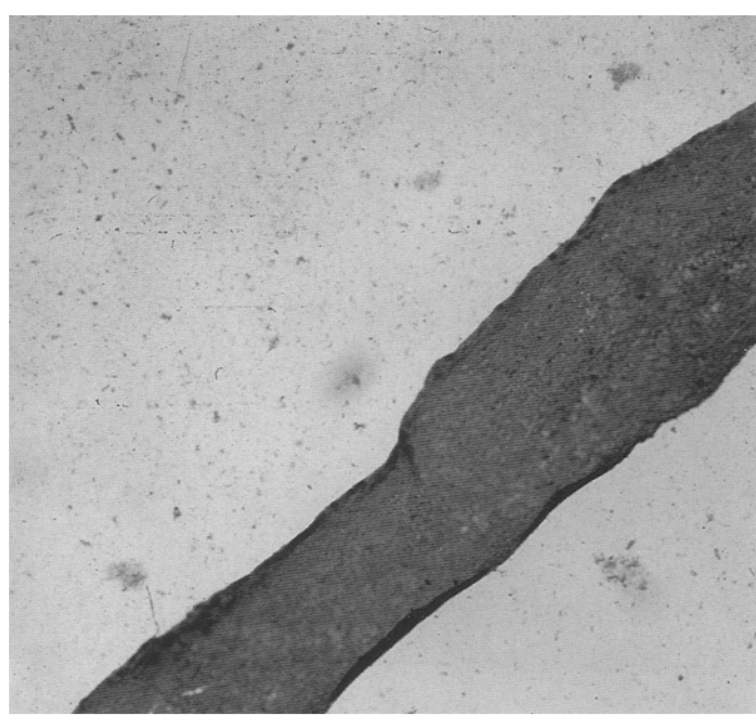

Fig. 3. Human endothelium on xenografts expresses class II antigens. Anti-DR antibody was used to examine whether human endothelium found on reendothelialized valvular xenografts expresses class II antigens. Positively stained monolayer is identified. Stain is weak, showing that human endothelium expresses low levels of class II antigens (original magnification $\times 90$ ).

preservation contributes much to their fate. In addition, Grabenwoger and colleagues ${ }^{13}$ have recently pointed out the significance of phagocytosis in the subsequent degeneration of bioprotheses. This supports the data that enzymes present in explanted valves were found to be strong in proteolytic activity. ${ }^{14}$

The antigenicity of valves was demonstrated very early by our group and others. ${ }^{5,15}$ Although the degeneration of allografts and xenografts has been clinically documented, the immunologic processes underlying this are poorly understood. Our data show that human endothelial cells constitutively present on allografts express MHC antigens and some adhesion molecules. We also show that although valvular grafts degenerate with time, a fine layer of recipient endothelial cells is present. This suggests that reendothelialization of valvular grafts is a natural repair and replacement procedure that occurs in vivo. In another study we showed that during acute rejection of cardiac grafts a mononuclear cell infiltration within the valvular allograft can be observed (data not shown). The presence of these cells suggests that valves are immunogenic and are recognized as foreign antigen just like any other tissue. In conclusion, we suggest that the degenera- 
tion of valves after implantation may not only be caused by mechanical reasons, but also by local immunologic processes that occur on the grafts. Further reendothelialization of porcine valves appears to be a natural repair process after xenogenic valve implantation.

\section{REFERENCES}

1. Lam CR, Aram HH, Munnell ER. An experimental study of aortic valve allografts. Surg Gynecol Obstet 1952;94:129-35.

2. Murray G. Homologous aortic valve segment transplants as surgical treatment of aortic and mitral insufficiency. Angiology 1956;7:446-71.

3. Khatib HE, Lupinetti FM. Antigenicity of fresh and cryopreserved rat valve allografts. Transplantation 1990;49:765-7.

4. Lupinetti FM, Christy JP, King DM, et al. Immunogenicity, antigenicity, and endothelial viability of aortic valves preserved at $4^{\circ} \mathrm{C}$ in a nutrient medium. $\mathrm{J}$ Card Surg 1991;6:454-61.

5. Thiede A, Timm C, Bernhard A, et al. Studies on the antigenicity of vital allogeneic valve leaflet transplants in immunogenetically controlled strain combinations. Transplantation 1978;26:391-5.

6. Clarke DR, Campbell DN, Hayward AR, et al. Degeneration of aortic valve allografts in young recipients. J Thorac Cardiovasc Surg 1993;105:934-42.

7. Simon A, Zavazava $\mathbf{N}$, Sievers $\mathbf{H H}$, et al. In vitro cultivation and immunogenicity of human cardiac endothelium. J Card Surg 1993;8:656-65.
8. Yankah AC, Hetzer R. Procurement and viability of cardiac valve allografts. In: Yankah AC, Hetzer R, Miller DC, et al., eds. Cardiac valve allografts 19621987. Darmstadt, Germany: Steinkopff, 1987:23-6.

9. Lupinetti FM, Cobb S, Koschos HC, et al. Effect of immunological differences on rat aortic valve allograft calcification. J Card Surg 1992;7:65-70.

10. O'Connell JB, Renlund DG, Bristow MR, et al. Detection of allograft endothelial cells of recipient origin following $\mathrm{ABO}-$ compatible, nonidentical cardiac transplantation. Transplantation 1991;51:438-42.

11. Eberl T, Siedler S, Schumacher B, et al. Experimental in vitro endothelialization of cardiac valve leaflets. Ann Thorac Surg 1992;53:487-92.

12. Ross D, Jackson M, Davies J. The pulmonary autograft: a permanent aortic valve. Eur J Cardiothorac Surg 1992;6:113-6.

13. Grabenwoger $M$, Grimm $M$, Eybl E, et al. New aspects of the degeneration of biosynthetic heart valves after long-term implantation. J THORAC CARDIOVASC SURG 1992;104:14-21.

14. Simionescu D, Simionescu D, Deac R. Detection of remnant proteolytic activities in unimplanted glutaraldehyde-treated bovine pericardium and explanted cardiac bioprotheses. J Biomed Mater Res 1993;27: 821-9.

15. Tector AJ, Boyd WC, Korns ME. Aortic valve allograft rejection. J THORAC CARDIOvasC SURG 1971; 62:592-601.

\section{Availability of JouRNAL back issues}

As a service to our subscribers, copies of back issues of THE Journal of THoracic and Cardiovascular Surgery for the preceding 5 years are maintained and are available for purchase from the publisher, Mosby-Year Book, Inc., at a cost of $\$ 12.00$ per issue. The following quantity discounts are available: $25 \%$ off on quantities of 12 to 23 , and one third off on quantities of 24 or more. Please write to Mosby-Year Book, Inc., Subscription Services, 11830 Westline Industrial Drive, St. Louis MO 63146-3318, or call (800)453-4351 or (314)453-4351 for information on availability of particular issues. If unavailable from the publisher, photocopies of complete issues are available from University Microfilms International, 300 N. Zeeb Rd., Ann Arbor, MI 48106, (313) $761-4700$. 